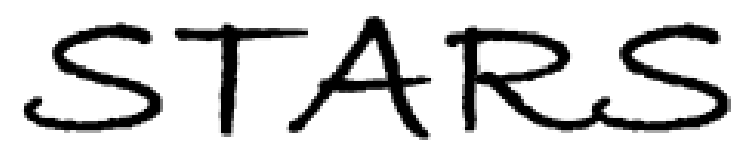

University of Central Florida

STARS

$1-1-2011$

\title{
Third-order nonlinear optical response and photoluminescence characterization of tellurite glasses with different alkali metal oxides as network modifiers
}

\author{
R. Castro-Beltrán \\ H. Desirena \\ University of Central Florida \\ G. Ramos-Ortiz \\ E. De la Rosa \\ G. Lanty
}

Find similar works at: https://stars.library.ucf.edu/facultybib2010 Sneverstityage Eornafditipallauthibfaries http://library.ucf.edu

This Article is brought to you for free and open access by the Faculty Bibliography at STARS. It has been accepted for inclusion in Faculty Bibliography 2010 s by an authorized administrator of STARS. For more information, please contact STARS@ucf.edu.

\section{Recommended Citation}

Castro-Beltrán, R.; Desirena, H.; Ramos-Ortiz, G.; De la Rosa, E.; Lanty, G.; Lauret, J. S.; Romero-Servin, S.; and Schülzgen, A., "Third-order nonlinear optical response and photoluminescence characterization of tellurite glasses with different alkali metal oxides as network modifiers" (2011). Faculty Bibliography 2010s. 1138.

https://stars.library.ucf.edu/facultybib2010/1138

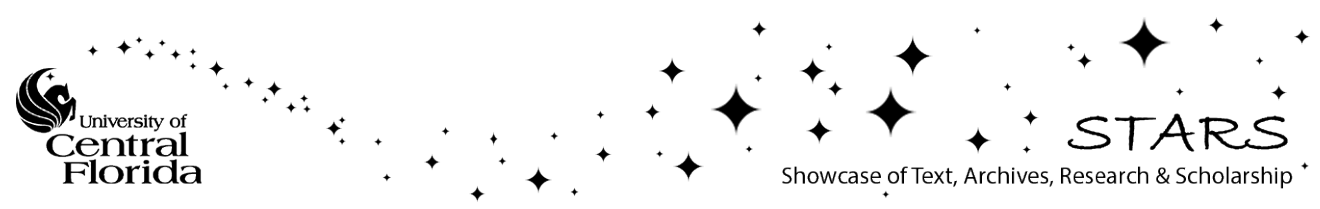




\section{Authors}

R. Castro-Beltrán, H. Desirena, G. Ramos-Ortiz, E. De la Rosa, G. Lanty, J. S. Lauret, S. Romero-Servin, and A. Schülzgen 


\section{Third-order nonlinear optical response and photoluminescence characterization of tellurite glasses with different alkali metal oxides as network modifiers}

Cite as: J. Appl. Phys. 110, 083110 (2011); https://doi.org/10.1063/1.3654018

Submitted: 08 July 2011 . Accepted: 15 September 2011 . Published Online: 24 October 2011

R. Castro-Beltrán, H. Desirena, G. Ramos-Ortiz, E. De la Rosa, G. Lanty, J. S. Lauret, S. Romero-Servin, and A. Schülzgen

ARTICLES YOU MAY BE INTERESTED IN

Femtosecond nonlinear optical properties of tellurite glasses

Applied Physics Letters 89, 171917 (2006); https://doi.org/10.1063/1.2364467

The optical properties of tellurite glasses

Journal of Applied Physics 72, 1774 (1992); https://doi.org/10.1063/1.351649

Electronic oxide polarizability and optical basicity of simple oxides. I

Journal of Applied Physics 79, 1736 (1996); https://doi.org/10.1063/1.360962

Applied Physics Reviews Now accepting original research 


\title{
Third-order nonlinear optical response and photoluminescence characterization of tellurite glasses with different alkali metal oxides as network modifiers
}

\author{
R. Castro-Beltrán, ${ }^{1}$ H. Desirena, ${ }^{1,2}$ G. Ramos-Ortiz, ${ }^{1, a)}$ E. De la Rosa, ${ }^{1, a)}$ G. Lanty, ${ }^{3}$ \\ J. S. Lauret, ${ }^{3}$ S. Romero-Servin, ${ }^{1}$ and A. Schülzgen ${ }^{2}$ \\ ${ }^{1}$ Centro de Investigaciones en Óptica León, A.P. 1-948, León, Gto. 37000, Mexico \\ ${ }^{2}$ School of Optics and Center for Research and Education in Optics and Lasers, University of Central Florida, \\ Orlando, Florida 32816-2700, USA \\ ${ }^{3}$ Laboratoire de Physique de la Matière Condesée, Ecole Normale Supérieure, París Cedex 05, France
}

(Received 8 July 2011; accepted 15 September 2011; published online 24 October 2011)

\begin{abstract}
Studies of the third-order nonlinear optical properties in $\mathrm{TeO}_{2}-M \mathrm{O}-R_{2} \mathrm{O}$ glasses with three different alkali metal oxides $R_{2} \mathrm{O}(R=\mathrm{Li}, \mathrm{Na}, \mathrm{K})$ as network modifiers and two network intermediates $M \mathrm{O}$ $(M=\mathrm{Zn}, \mathrm{Mg})$ are reported. The influence of such modifiers and intermediates on the nonlinear optical properties of these glasses was investigated using the standard Z-scan and the thermally managed Z-scan techniques under femtosecond pulse excitation at $800 \mathrm{~nm}$. For different modifiers and intermediates, the nonlinear refraction indices $n_{2}$ of these glasses varied in the range 1.31-2.81 $\left(\times 10^{-15} \mathrm{~cm}^{2} / \mathrm{W}\right)$. It was found that $n_{2}$ increases as the ionic radius of both network modifiers and intermediates decreases. Furthermore, the measurements show that the contribution from thermo-optical effects to the nonlinear refraction index is negligible for all of the studied glass compositions. In addition, the effect of modifiers and intermediates in the formation of localized states in the vicinity of the optical bandgap was also studied through photoluminescence experiments. These experiments revealed the presence of two emission bands (red and blue) originating from these localized states that can be populated after optical excitation and subsequent relaxation. (C) 2011 American Institute of Physics. [doi:10.1063/1.3654018]
\end{abstract}

\section{INTRODUCTION}

Recently, $\mathrm{TeO}_{2}$-based optical glasses have received much attention for applications, such as laser devices, broadband amplifiers, up-conversion emission, and photonic crystal fibers. ${ }^{1-6}$ Furthermore, tellurite glasses exhibit large nonlinear (NL) refractive indices $n_{2}$, which is a desirable property for all-optical switching devices. ${ }^{7-11}$ For this photonic application, tellurite glasses offer advantages over both semiconductors and organic materials because of their good transmission in the visible and infrared regions (up to $6 \mu \mathrm{m}$ ), fast response times, good mechanical properties, as well as affordability and processability. Moreover, when compared with other glass families, tellurites offer relatively low phonon energies and are mostly less toxic and more chemically and thermally stable. ${ }^{4-12}$

In the development of tellurite glasses for optical signal processing and all-optical switching applications, it is necessary to combine large NL refractive indices with desirable thermo-mechanical properties. These optical and thermomechanical properties depend on the glass composition, and consequently, it results of interest to know how they are affected by the use of different glass formers and various possible network modifiers. Recently, a lot of work on composition and material properties has been reported for different glass families. For instance, the incorporation of alkali

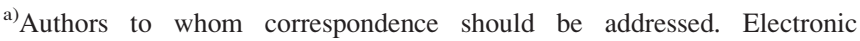
addresses: garamoso@cio.mx and elder@cio.mx.
}

metals as network modifiers has been studied in order to improve the thermo-mechanical properties as well as the optical properties. ${ }^{10-17}$ In regard to tellurite glasses, we recently reported the effect of alkali metal oxides $R_{2} \mathrm{O}$ $(R=\mathrm{Li}, \mathrm{Na}, \mathrm{K}, \mathrm{Rb}$, and $\mathrm{Cs})$ and network intermediates $M O$ $(M=\mathrm{Zn}, \mathrm{Mg}, \mathrm{Ba}$, and $\mathrm{Pb})$ on the thermo-mechanical and chemical properties. ${ }^{18}$ In this study, the experimental results showed that alkali metals with small ionic radii decrease the thermal expansion coefficient, the glass transition temperature (Tg), and the chemical durability. As for the optical properties, the results showed that small ionic radii also favor the increase of the linear refractive index $n$, while third-harmonic generation (THG) experiments demonstrated also an increase in the nonlinear third-order susceptibilities of the type $\chi^{(3)}(-3 \omega, \omega, \omega, \omega)$ for fundamental wavelength at $1550 \mathrm{~nm}$. It is worth mentioning that THG is an easy technique for a quick screening of nonlinearities in optical materials, but it does not provide the value of the NL refractive index $n_{2}$, the latter parameter being of paramount interest for all-optical switching applications. Motivated by this fact, in this work, we present direct measurements of $n_{2}$ for a series of $\mathrm{TeO}_{2}$ glasses composed of various network modifiers and intermediates.

To explore the effect of alkali metals and network intermediates on the nonlinear refractive index of tellurite glasses, compositions, such as $\mathrm{TeO}_{2}-M \mathrm{O}-R_{2} \mathrm{O}$, were studied. For this purpose, four $\mathrm{TeO}_{2}$-based glasses were prepared in a way that they all had the same molar concentration of $\mathrm{TeO}_{2}$. The magnitude of the NL refractive index $n_{2}$ was determined 
using the standard Z-scan technique. ${ }^{19}$ Additionally, the thermally managed (TM) Z-scan technique ${ }^{20}$ was also employed in order to identify possible contributions to $n_{2}$ from thermooptical effects. Note that the use of different network modifiers and intermediates in tellurite glasses introduces changes in the coefficient of thermal expansion which can influence the overall nonlinear response. Therefore, we applied a TM $\mathrm{Z}$-scan technique that enables one to discriminate between nonlinearities of pure electronic origin and nonlinearities due to accumulative thermal effects. This information is important, since only nonlinear electronic processes can provide fast material response (fs to ps), which is of interest for photonic application, including optical processing of information.

Finally, to obtain more information about the electronic structure in tellurite glasses, the effect of modifiers and intermediates on the formation of localized states was also studied through photoluminescence and pump-probe experiments.

\section{EXPERIMENTS}

\section{A. Nonlinear materials}

The glasses studied here with composition (mol. \%) $70 \mathrm{TeO}_{2}-20 M \mathrm{O}-10 R_{2} \mathrm{O}$ were prepared using the conventional method of powder melting and annealing process as reported elsewhere. ${ }^{18}$ The network intermediates are $M=$ zinc ( $\mathrm{Zn}$ ) or magnesium $(\mathrm{Mg})$, and the network modifiers are $R=$ lithium $(\mathrm{Li})$, sodium $(\mathrm{Na})$, and potassium $(\mathrm{K})$. Reagent-grade tellurium oxide $\left(\mathrm{TeO}_{2}\right)$, zinc oxide $(\mathrm{ZnO})$, magnesium oxide $(\mathrm{MgO})$, potassium carbonate $\left(\mathrm{K}_{2} \mathrm{CO}_{3}\right)$, sodium carbonate $\left(\mathrm{NaCO}_{3}\right)$, and lithium oxide $\left(\mathrm{Li}_{2} \mathrm{O}\right)$ were used as starting materials. Calculated quantities of chemicals were mixed in a glass dish and melted in an electric furnace at $900^{\circ} \mathrm{C}$ for one hour using an alumina crucible. Each melt was cast into a preheated aluminum mold with a size of $5 \times 13 \times 13 \mathrm{~mm}^{3}$. Subsequently, it was removed from the mold and transferred to a furnace for annealing process at a temperature from $270^{\circ} \mathrm{C}$ to $380^{\circ} \mathrm{C}$, depending on the glass composition, for approximately $21 \mathrm{~h}$. For characterization, the samples were cut and polished to obtain $\sim 1 \mathrm{~mm}$ thick slabs. Special care was taken to polish the samples in order to reduce errors in Z-scan experiments due to glass imperfections. The glass compositions and code used in this work for each sample are summarized in Table I. This table also shows the linear refractive index at $800 \mathrm{~nm}$ obtained from calculated dispersion curves that resulted from direct measurements of the refractive index at 633,830 , and $1550 \mathrm{~nm}$ through the use of the prism coupler technique. ${ }^{18}$

TABLE I. Code, glass composition (mol. \%), and refractive index for the tellurite glasses used in this study.

\begin{tabular}{lccccccc}
\hline \hline Glass & $\mathrm{TeO}_{2}$ & $\mathrm{ZnO}$ & $\mathrm{MgO}$ & $\mathrm{K}_{2} \mathrm{O}$ & $\mathrm{Na}_{2} \mathrm{O}$ & $\mathrm{Li}_{2} \mathrm{O}$ & $n(800 \mathrm{~nm})$ \\
\hline $\mathrm{TeZnK}$ & 70 & 20 & - & 10 & - & - & 1.887 \\
$\mathrm{TeZnNa}$ & 70 & 20 & - & - & 10 & - & 1.918 \\
$\mathrm{TeZnLi}$ & 70 & 20 & - & - & - & 10 & 1.956 \\
TeMgLi & 70 & - & 20 & - & - & 10 & 1.919 \\
\hline \hline
\end{tabular}

\section{B. Z-scan}

The Z-scan technique was used to characterize the NL optical properties of the tellurite glasses. This technique is based on the NL phase measurement of a laser beam propagating through the sample under study and provides a sensitive method to measure the real and imaginary parts of the complex NL refractive index. ${ }^{19}$ Different physical mechanisms, i.e., thermal and nonthermal, can contribute significantly to the measured values of $n_{2}$. For photonic glasses, only electronic (nonthermal) nonlinearities are required; therefore, it is necessary to anticipate the contributions of induced thermal lensing effects on the value of $n_{2}$. In order to discriminate between the thermal and electronic nonlinearities, Gnoli et $a l .{ }^{20}$ introduced a modification to the standard Z-scan technique, the so-called TM Z-scan. In brief, it involves the time evolution measurement of the normalized transmittance at the valley and the peak of a Z-scan signal that is obtained using a femtosecond laser with a high repetition rate. To do this, a laser beam is modulated by a mechanical chopper placed in the focus of a Keplerian telescope. Using this modulated beam in the Z-scan set-up results in a temporal resolution of the system that is determined by the chopper opening time. In our case, special care has been taken to produce a resolution of $10 \mu$ s by a right combination of the finite size of the beam waist in the Keplerian telescope, special modification in the slots of the chopper wheel, and the angular velocity of the chopper wheel. The so-obtained resolution time was about double with respect to the values reported by other authors. ${ }^{11,20-22}$ By extrapolating the time-resolved Z-scan signals to the time $t=0$ (determined by the opening time of the chopper), the change in normalized transmittance between peak and valley has been obtained at very early times before thermal effects start to influence the Z-scan signal. From these extrapolated values, the nonthermal NL refractive indices have been calculated. In the present work, the TM Z-scan was implemented using pulses of $100 \mathrm{fs}$ duration centered at $800 \mathrm{~nm}$. The pulse trains with $80 \mathrm{MHz}$ repetition rate have been generated by a Ti:sapphire oscillator (Tsunami, SpectraPhysics). With this oscillator, typical peak intensities at the sample position were in the range of $1-10 \mathrm{GW} / \mathrm{cm}^{2}$. In these experiments, the Rayleigh length was $2.45 \mathrm{~mm}$ and the aperture transmittance at far field was $S=0.4$. The glass characterization was also performed with the standard Z-scan technique, applying higher intensity pulses with 280 fs duration from a femtosecond Ti:sapphire regenerative amplifier at $1 \mathrm{KHz}$ repetition rate.

\section{Photoluminescence and pump-probe experiments}

Photoluminescence (PL) spectra from tellurite glass samples were obtained after excitation with the third-harmonic $(355 \mathrm{~nm})$ of a pulsed Nd:YAG laser $(7 \mathrm{~ns}$ pulses at $10 \mathrm{~Hz}$ repetition rate) and with the second-harmonic $(244 \mathrm{~nm})$ of a continuous wave argon laser. In addition, the dynamics of electronic excitations in the glasses were studied through time-resolved pump-probe experiments. In this case, the transient change of transmission of the samples was measured in a non-degenerate setup employing femtosecond pump pulses at $440 \mathrm{~nm}(2.8 \mathrm{eV})$ with typical intensities in the range of 
$0.38-1.2 \mathrm{~mJ} / \mathrm{cm}^{2}$ and probe pulses at $516 \mathrm{~nm}(2.4 \mathrm{eV})$ with intensities a hundred times weaker with respect to pump pulses. The instrument response was evaluated through the cross correlation between the pump and probe pulses and gave a temporal resolution of $120 \mathrm{fs}$.

\section{RESULTS AND DISCUSSIONS}

\section{A. Absorption and optical bandgap}

To estimate the optical bandgap of the samples, linear absorption measurements have been performed. The absorption spectra were measured from 300 to $3000 \mathrm{~nm}$ using a spectrophotometer (Lambda 900, Perkin-Elmer) and are shown in Fig. 1. The tellurite glasses were optically transparent in the range of wavelengths from $450 \mathrm{~nm}(2.75 \mathrm{eV})$ to $2500 \mathrm{~nm}$ $(0.49 \mathrm{eV})$, while a weak tail of linear absorption was present at $400 \mathrm{~nm}(3.10 \mathrm{eV})$. The optical bandgap energy $E_{\mathrm{g}}$ for each sample was obtained from its absorption spectrum, following the Tauc approach. ${ }^{23}$ By plotting $\sqrt{\alpha \cdot h \nu}$ as a function of photon energy $h \nu\left(\alpha\right.$ is the absorption coefficient in $\left.\mathrm{cm}^{-1}\right)$ and extrapolating the linear regions of this function to zero absorption, optical bandgap values of $3.55 \mathrm{eV}, 3.59 \mathrm{eV}, 3.50 \mathrm{eV}$, and $3.48 \mathrm{eV}$ were obtained for TeZnK, TeZnNa, TeZnLi, and $\mathrm{TeMgLi}$, respectively. These values are larger than those reported in the literature for pure $\mathrm{TeO}_{2}$ glasses, which are in the range $3.15-3.37 \mathrm{eV},{ }^{24,25}$ which means that the inclusion of modifiers and network intermediates shifts the bandgap to higher energies. Our samples also show larger $E_{\mathrm{g}}$ than in tellurite glasses that use $\mathrm{Bi}$ as a network intermediate, i.e., $\mathrm{TeO}_{2}$ $\mathrm{Bi}_{2} \mathrm{O}_{3}-\mathrm{ZnO},{ }^{26}$ but are smaller than those reported for rare earth-doped tellurite glasses. ${ }^{24}$

\section{B. Nonlinear optical properties}

The samples exhibited a self-focusing effect in the Z-scan experiments. In Fig. 2(a), examples of Z-scan traces for TeZnNa and TeZnK glasses are shown. Here, a peak preceded by a valley in the normalized transmittance clearly indicates

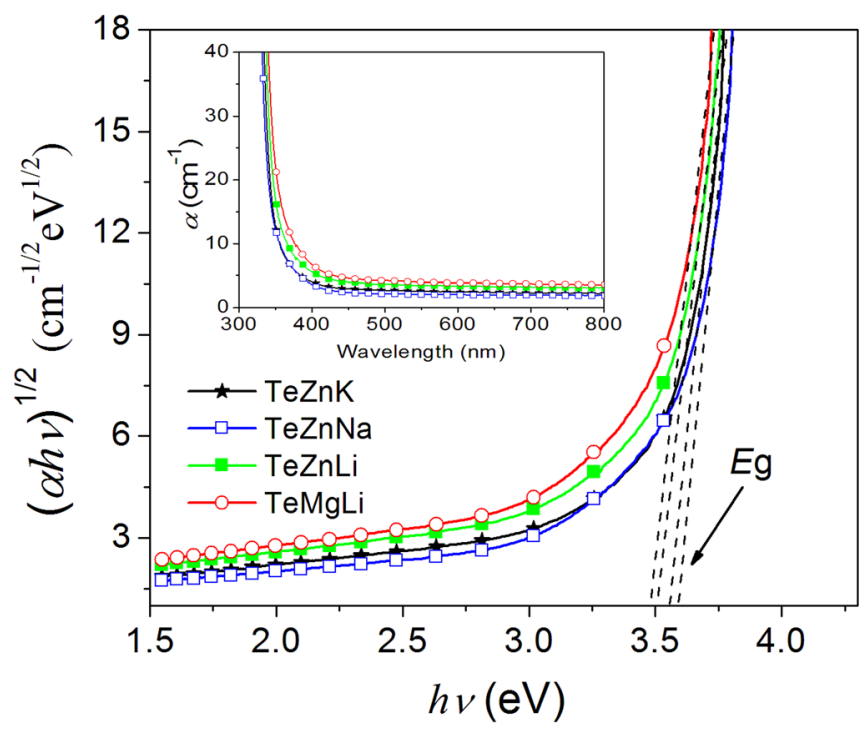

FIG. 1. (Color online) Dependence of $(\alpha \cdot h \nu)^{1 / 2}$ on the photon energy for tellurite glasses. Inset: absorption spectra of the tellurite glasses.
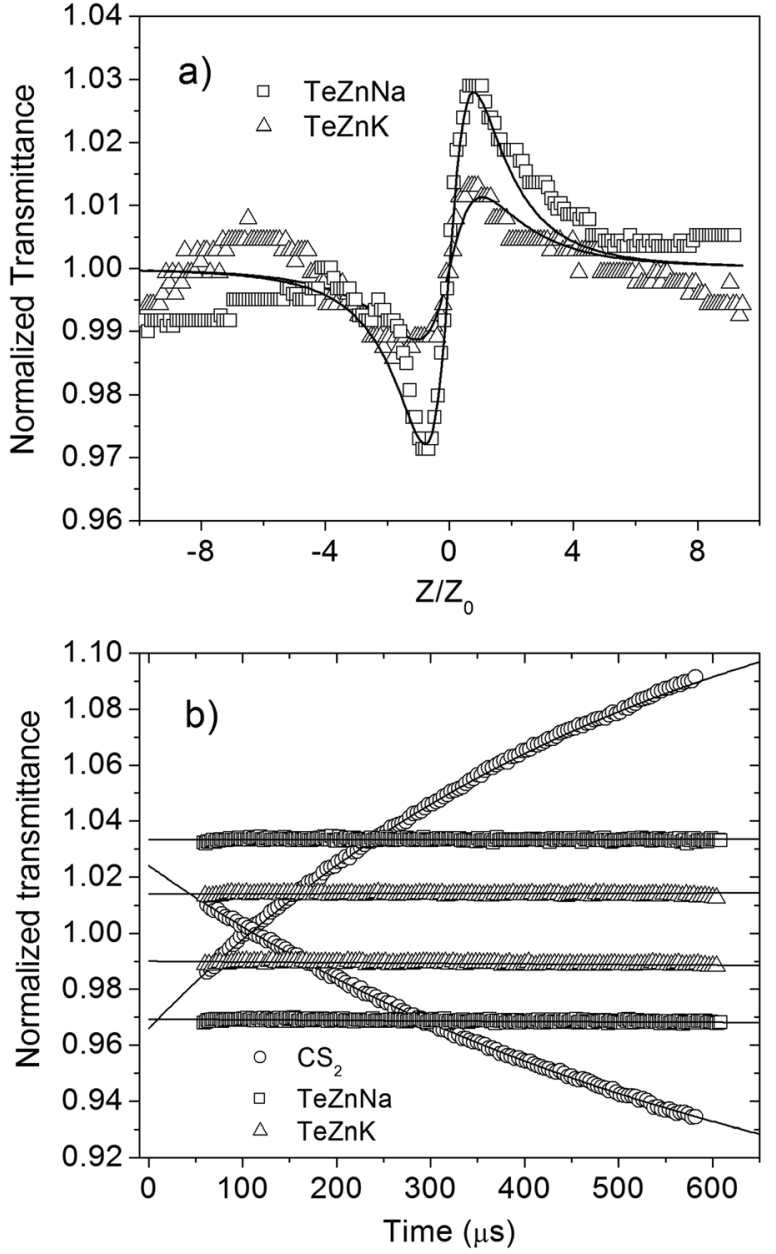

FIG. 2. (a) Normalized transmittance of standard Z-scan measurements for $\mathrm{TeZnNa}$ and TeZnK. The continuous lines are fittings to the experimental data. (b) Thermally managed Z-scan signals at valleys and peaks of traces shown in (a). The traces of $\mathrm{CS}_{2}$ are included as reference.

that glasses have a positive NL refractive index. These traces were obtained with a train of fs pulses at high repetition rate from the Ti:sapphire oscillator with a peak intensity of $9.0 \mathrm{GW} / \mathrm{cm}^{2}$ at the sample position. Figure 2(b) shows the temporal evolution of the TM Z-scan signals at the positions of minimum (valley) and maximum (peak) transmittance for these two glasses. The signals exhibit negligible time evolution. The changes in normalized transmittance between peak and valley immediately after excitation have been obtained by extrapolating the evolution curves to the time $t=0$, and the corresponding electronic values of $n_{2}$ have been found to be 1.31 and $2.33\left(\times 10^{-15} \mathrm{~cm}^{2} / \mathrm{W}\right)$ for TeZnK and TeZnNa, respectively. Figure 2(b) also shows the signal obtained from the standard reference $\mathrm{CS}_{2}$ (contained in a $\sim 1 \mathrm{~mm}$ quartz cell). In this case, the crossing of the two TM Z-scan curves reveals the presence of both self-focusing (electronic) and selfdefocusing (thermal) effects that compete during the time that the sample is exposed to the train of fs pulses. It is evident that, in $\mathrm{CS}_{2}$, the electronic nonlinear response dominates at early times, but the thermal nonlinearity dominates over the electronic response of the material after $\sim 100 \mu$ s, as shown by the crossing of the TM Z-scan curves at such time. By extrapolating the evolution curves of $\mathrm{CS}_{2}$, the electronic value of $n_{2}$ resulted to be $2.11 \times 10^{-15} \mathrm{~cm}^{2} / \mathrm{W}$, which is in good agreement 
TABLE II. Values of $n_{2}$ and the third-order nonlinear susceptibility $\chi^{(3)}(-\omega ; \omega,-\omega, \omega)$ measured through thermally managed Z-scan technique.

\begin{tabular}{lcc}
\hline \hline Sample & $n_{2}\left[10^{-15} \mathrm{~cm}^{2} / \mathrm{W}\right]$ & $\chi^{(3)}\left(10^{-13} \mathrm{esu}\right)$ \\
\hline TeZnK & $1.31 \pm 0.20$ & 1.15 \\
TeZnNa & $2.33 \pm 0.42$ & 2.06 \\
TeZnLi & $2.37 \pm 0.40$ & 2.10 \\
TeMgLi & $2.81 \pm 0.5$ & 2.5 \\
$\mathrm{CS}_{2}$ & $2.11 \pm 0.45$ & 1.87 \\
\hline
\end{tabular}

with values previously reported for this material ${ }^{27}$ and, thus, validates the calibration of our experimental apparatus. Following this procedure, the $n_{2}$ values for glasses TeZnLi and TeM$\mathrm{gLi}$ were found to be 2.37 and $2.81\left(\times 10^{-15} \mathrm{~cm}^{2} / \mathrm{W}\right)$, respectively. For these glasses also, no temporal evolution of the TM Z-scan signal was observed. Table II summarizes the NL refractive indices determined for our tellurite glasses as well as the real part of the third-order nonlinear susceptibility $\chi^{(3)}(-\omega, \omega, \omega, \omega)$. Both quantities are related through $n_{2}$ $=3 \chi^{(3)} / 4 \varepsilon_{0} n^{2} c$, where $n$ is the linear refractive index.

The absence of a temporal evolution in the TM Z-scan signals from the tellurite glasses studied in this work clearly shows that their third-order optical nonlinearity originated from pure electronic polarization. By examining Table II for the glasses with the network intermediate $\mathrm{Zn}$, it is observed that $n_{2}$ increases in the following order $\mathrm{TeZnK}<\mathrm{TeZnNa}<\mathrm{TeZnLi}$, although the sample with $\mathrm{Li}$ as modifiers is barely larger than in the case of Na. A further increase of nonlinearity is also observed when $\mathrm{Zn}$ is replaced by $\mathrm{Mg}$ as intermediate. The nonlinear response is related with the degree of hyperpolarizability of the sample as a result of the structural changes inside the arrangement with the presence of modifiers and intermediates. Therefore, the trend exhibited by samples with $\mathrm{Zn}$ as intermediate can be attributed to the decrease in ionic radius from $\mathrm{K}$ to Li through $\mathrm{Na}$ that leads to a modification of the polarizability per unit volume. ${ }^{28}$ Similarly, the nonlinear response increases when $\mathrm{Zn}$ is substituted by $\mathrm{Mg}$, which has a smaller ionic radius. From this concept, it follows that the number of ions per unit volume might increase as the ionic radii of the network modifiers and/or intermediates decrease. The corresponding ion radii for $\mathrm{K}, \mathrm{Na}, \mathrm{Li}, \mathrm{Zn}$, and $\mathrm{Mg}$ are $1.33,0.95,0.68,0.74$, and $0.65 \AA$, respectively. Thus, more ions per unit volume can be polarized using $\mathrm{Li}$ and $\mathrm{Mg}$ as modifier and intermediate, respectively, and consequently, the nonlinear response is larger. In the opposite case, fewer ions per unit volume can be polarized with the use of $\mathrm{K}$ and $\mathrm{Zn}$, and consequently, the nonlinear response is weaker (see Table II). This trend was also observed in the nonlinear susceptibilities of the type $\chi^{(3)}(-3 \omega, \omega, \omega, \omega)$ measured by means of THG at $1.9 \mu \mathrm{m}$ for binary glasses of the type $\mathrm{TeO}_{2}-R_{2} \mathrm{O}$ with $R=\mathrm{K}, \mathrm{Na}, \mathrm{Li}^{28}$ As for ternary glasses, a recent study on the optical properties of codoped tellurite glasses based in the matrix $\mathrm{TeO}_{2}-\mathrm{ZnO}-\mathrm{Na}_{2} \mathrm{O}$ showed a NL refractive index of $1.90 \times 10^{-15} \mathrm{~cm}^{2} / \mathrm{W}$ at $800 \mathrm{~nm} .^{11}$ The matrix reported in that work was similar to our TeZnNa sample, although with a concentration of $5 \mathrm{~mol}$. \% for the modifier $\mathrm{Na}_{2} \mathrm{O}$ (and $20 \mathrm{~mol}$. \% for $\mathrm{ZnO}$ ). Thus, the values of $n_{2}$ measured in the present work for TeZnNa and in Ref. 11 for a similar glass composition show good agreement.
The NL refractive index for the series of glasses with $\mathrm{Zn}$ as the network intermediate followed the order suggested by the semiempirical Miller's rule (stating that materials with larger linear refractive index possess larger NL refractive index), although they do not vary in proportion to the variation of their linear refractive index. However, the rule fails with the introduction of $\mathrm{Mg}$ as the network intermediate (see Table II). According to Miller's rule, TeMgLi shows an unexpected larger nonlinearity in comparison to TeZnLi, being their linear refractive index 1.919 and 1.956 at 800 $\mathrm{nm}$, respectively. In this case, the nonlinearity increased when $\mathrm{Zn}$ was replaced by $\mathrm{Mg}$ in the glass composition to obtain a maximum value of $2.81 \times 10^{-15} \mathrm{~cm}^{2} / \mathrm{W}$. This is not surprising, as other authors have also observed the failure of Miller's rule. ${ }^{29,30}$ Further, in our previous work, ${ }^{18}$ it was also observed that the introduction of $\mathrm{Mg}$ to replace $\mathrm{Zn}$ in the glass composition increased the third-order susceptibility tensor associated with the optical nonlinear effect of thirdharmonic generation for infrared wavelengths.

The Z-scan experiments demonstrate that the glass composition of our samples not only exhibit large values of $n_{2}$, but also have a good capacity to disperse the absorbed heat, precluding the appearance of accumulative thermal effects (thermal lensing) that could affect the nonlinear optical behavior. In our case, heat is produced from the residual linear absorption at $800 \mathrm{~nm}$ (at this wavelength, NL absorption was not experimentally detected for the maximum peak powers available in our TM Z-scan experiment). The absorption coefficient was estimated to be in the range of $0.1-1 \mathrm{~cm}^{-1}$, depending on the sample, and was calculated from the linear absorption spectra once the reflection losses were taken into account (typical transmittance in these glasses is about $80 \%$ ). The capacity of the samples to disperse the absorbed heat was tested in various experimental conditions. For instance, it is worth to mention that, in the TM Z-scan experiments, the illumination time was $\sim 1 \mathrm{~ms}$ (the time allowed for the chopper wheel to excite the sample) followed by $\sim 36 \mathrm{~ms}$ without illumination. This duty cycle was varied by simply changing the frequency of the chopper wheel, and no appreciable thermal effect was detected, even for longer times of illumination. Furthermore, standard Z-scan experiments were performed using a continuous wave titanium:sapphire laser with $400 \mathrm{~mW}$ output power. In this case, a constant transmittance was observed and no evidence of thermal lensing was detected. These results are interesting in view of the thermo-optical response measured in other glasses with different techniques. For instance, in binary and ternary tellurite glasses with composition (in mol. \%) $80 \mathrm{TeO}_{2}-20 \mathrm{Li}_{2} \mathrm{O}$ and $80 \mathrm{TeO}_{2}-15 \mathrm{Li}_{2} \mathrm{O}-$ $5 \mathrm{TiO}_{2}$ and with similar residual absorption than those corresponding to our samples $\left(\sim 1 \mathrm{~cm}^{-1}\right)$, a small thermal lens effect was detected under $\mathrm{cw} \mathrm{Ar}^{+}$laser excitation with $81 \mathrm{~mW}$ at $514 \mathrm{~nm}^{31}$

The values of NL refractive index $n_{2}$ for the tellurite glasses were independent of the peak intensities available for the laser oscillator used in the TM Z-scan experiments. In order to study the nonlinear response at much higher intensities, we analyzed the samples using the standard Z-scan under fs pulses delivered by a Ti:sapphire regenerative amplifier. Figure 3 shows an example of the nonlinear response of 


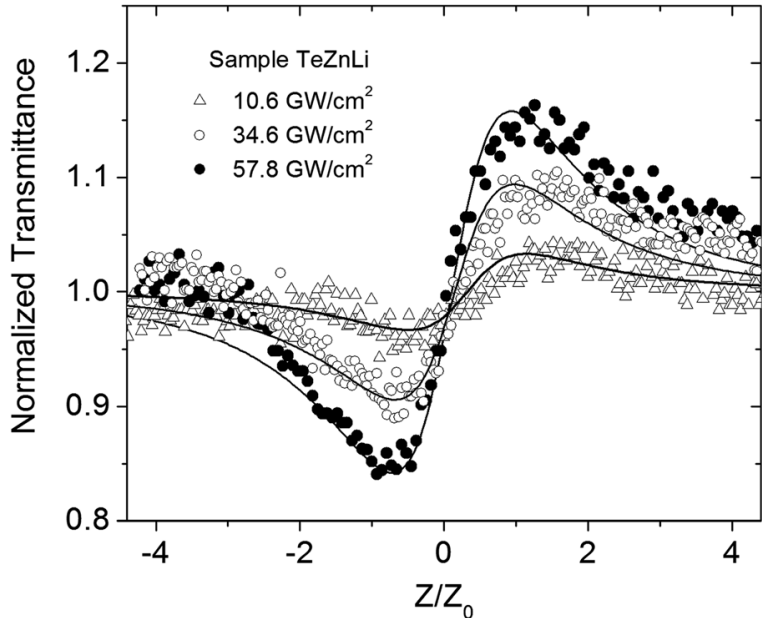

FIG. 3. Normalized transmittance in standard Z-scan measurements for TeZnLi under femtosecond excitation at $1 \mathrm{KHz}$ pulse repetition rate and different intensities. The continuous lines are fittings to the experimental data.

the TeZnLi sample at three different peak intensities: 10.6, 34.6 , and $57.8 \mathrm{GW} / \mathrm{cm}^{2}$. From these Z-scan traces, the values of $n_{2}$ resulted in $2.51,2.24$, and $2.07\left(\times 10^{-15} \mathrm{~cm}^{2} / \mathrm{W}\right)$, respectively, showing that at high peak intensities, the nonlinear response saturates. Figure 4 presents the values of the NL refractive index measured for all samples under study at 10.6 and $57.9 \mathrm{GW} / \mathrm{cm}^{2}$, and for comparison, the figure includes those values obtained with TM Z-scan at $9.0 \mathrm{GW} / \mathrm{cm}^{2}$. Notice the good agreement between the values of $n_{2}$ obtained at $10.6 \mathrm{GW} / \mathrm{cm}^{2}$ with a train of pulses at $1 \mathrm{KHz}$ and those obtained through TM Z-scan at $9.0 \mathrm{GW} / \mathrm{cm}^{2}$ with a train of pulses at $80 \mathrm{MHz}$. This confirms that the nonlinear response is free of accumulative thermal lensing effects, even upon excitation at high frequencies of repetition rate with intensities of the order of $10 \mathrm{GW} / \mathrm{cm}^{2}$. Moreover, at this level of intensities, the experiment with pulses at $1 \mathrm{KHz}$ also demonstrates (see Fig. 4) that the order in which the nonlinearities increase as a function of the modifiers is the same as that observed in TM Z-scan experiments. However, when the peak intensities are

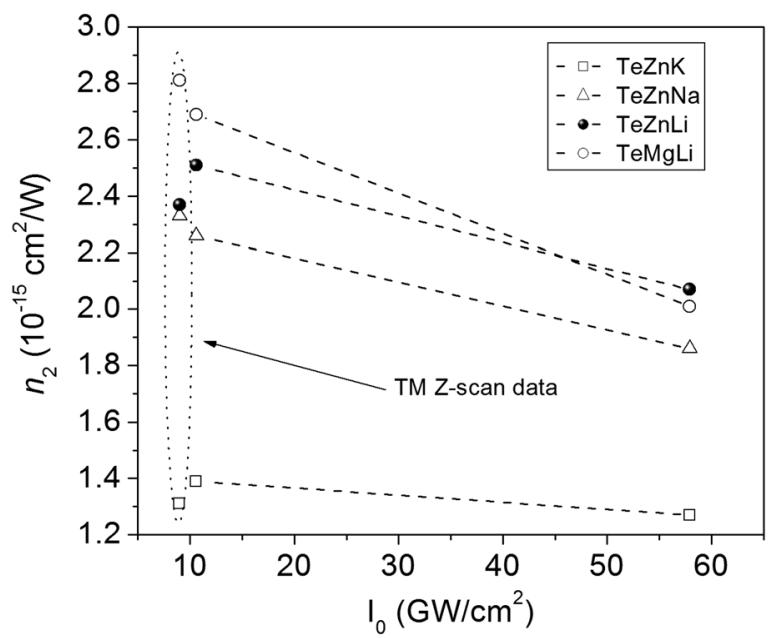

FIG. 4. Variation of $n_{2}$ as a function of intensities obtained under femtosecond excitation at $1 \mathrm{KHz}$ pulse repetition rate. For comparison, the values of $n_{2}$ obtained through TM Z-scan experiments at $80 \mathrm{MHz}$ pulse repetition rate are included. further increased, the values of $n_{2}$ decrease to some extent, as it is observed in Fig. 4 for the intensity of $57.8 \mathrm{GW} / \mathrm{cm}^{2}$. The decrease of the measured NL refractive indices at very high intensities might be associated with the appearance of nonlinearities of higher order or another physical process that modifies the material response. Nevertheless, it is worth to point out that, during these experiments, the glasses did not reveal apparent optical damage. This suggests that our samples are able to withstand high optical peak intensities without showing optical damage.

\section{Photoluminescence and transient absorption}

In Fig. 5, the PL of TeZnLi after UV excitation is shown. Clearly, position and structure of the emission bands change, depending on the excitation wavelength. All tellurite glass samples exhibited very similar emission spectra independently of the modifier or network intermediate in their composition, although TeZnLi showed the most intense PL signal. Low pump intensities were used to obtain these spectra. Figure 5 shows a red emission band centered at $650 \mathrm{~nm}$ $(1.90 \mathrm{eV})$ with a bandwidth of $140 \mathrm{~nm}$ after excitation at $355 \mathrm{~nm}(3.49 \mathrm{eV})$ and a blue emission band centered at $437 \mathrm{~nm}(2.83 \mathrm{eV})$ and with a bandwidth of $83 \mathrm{~nm}$ after excitation at $244 \mathrm{~nm}(5.08 \mathrm{eV})$. Both emission bands are the result of electron relaxation from electronic states, with energies lying within the bandgap, as illustrated in the energy scheme in Fig. 6, where ETb and ETr stand for the states responsible for blue and red emission bands, respectively. Those localized electronic states were produced by defects induced during the glass fabrication and can be probably related to the presence of both modifiers and network intermediates. Blue emission is likely associated with the presence of oxygen vacancies $(\Delta E \mathrm{~g} \sim 2.8 \mathrm{eV})$, as has been described for $\mathrm{ZnO}^{32}$ while the red emission is probably associated with sites where the modifiers $(\mathrm{Li}, \mathrm{Na}, \mathrm{K})$ constitute impurities. ${ }^{33,34}$ The observed PL dependence on the wavelength of excitation suggests two mechanisms for electronic transitions. Excitation at $355 \mathrm{~nm}$ promotes electrons from the valence band to the conductive band edge, and after nonradiative relaxations, ETr is populated; subsequently,

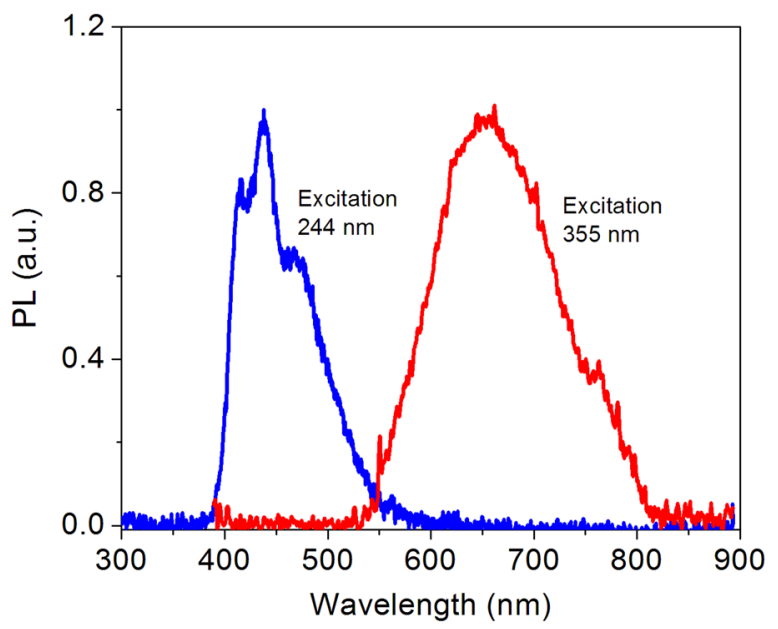

FIG. 5. (Color online) Normalized photoluminescence spectra for sample TeZnLi after excitation with $244 \mathrm{~nm}$ and $355 \mathrm{~nm}$ laser light. 


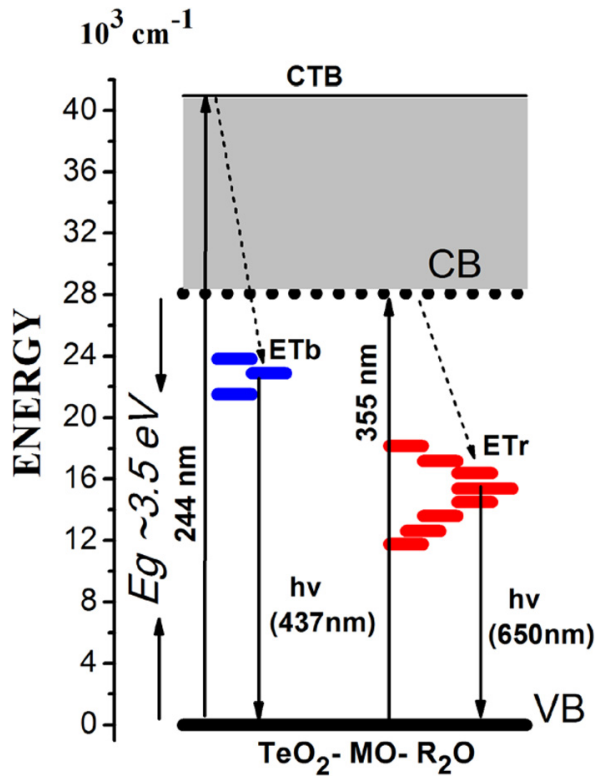

FIG. 6. (Color online) Schematic energy level diagrams for tellurite glasses. Dotted lines indicate nonradiative relaxations.

radiative decays generate the red PL band. For 244-nm excitation, the charge transfer band (CTB) is populated and successive nonradiative relaxations result in the population of the ETb state, which generates the blue PL band. This is in agreement with the analysis of the $\mathrm{CTB}$ in $\mathrm{TeO}_{2}$ glasses reported previously. ${ }^{35,36}$

To study the dynamics of the excited states, we performed nondegenarate pump-probe experiments with wavelengths corresponding to photon energies smaller than the optical bandgap. The samples were excited by strong pump pulses at $440 \mathrm{~nm}(2.8 \mathrm{eV})$, while delayed and weak probe pulses at $516 \mathrm{~nm}(2.4 \mathrm{eV})$ allowed us to measure transient changes of transmission $\Delta T$ induced by the pump pulses. The change in transmission is defined as $\Delta T=T_{p}-T$, where $T_{p}$ and $T$ are the transmission with and without pump, respectively. Figure 7 displays $\Delta T / T$ as a function of time delays between pump and probe pulses for the samples TeZnK, TeZnNa, TeZnLi, and TeMgLi. In this figure, the major component is a fast transient-induced absorption (i.e., decrease of transmission or negative values of $\Delta T / T$ ) of few hundreds of fs and a long and weak tail. This suggests that the decrease of $\Delta T / T$ observed in all the samples might be associated with induced absorption from the localized states to the conduction band. Notice that the wavelength of the pump corresponds to an energy $(2.8 \mathrm{eV})$ that is below the optical bandgap $(3.5 \mathrm{eV})$ of samples and thus excitation can only occur into the localized states, and from them, subsequent absorption of the probe beam promotes electrons to the conduction band. According to the excitation energies used in these experiments, the detected transient absorption should be mostly related to the localized states ETb. The transient absorption and dynamics of the localized states ETr were not obtained, since our excitation system could not be tuned to proper wavelength $(\sim 1.90 \mathrm{eV})$. Figure 7 also shows the presence of a fast $\Delta T / T$ increase $(\Delta T / T>0)$ just for early delays. In this case, that component of transient transmission

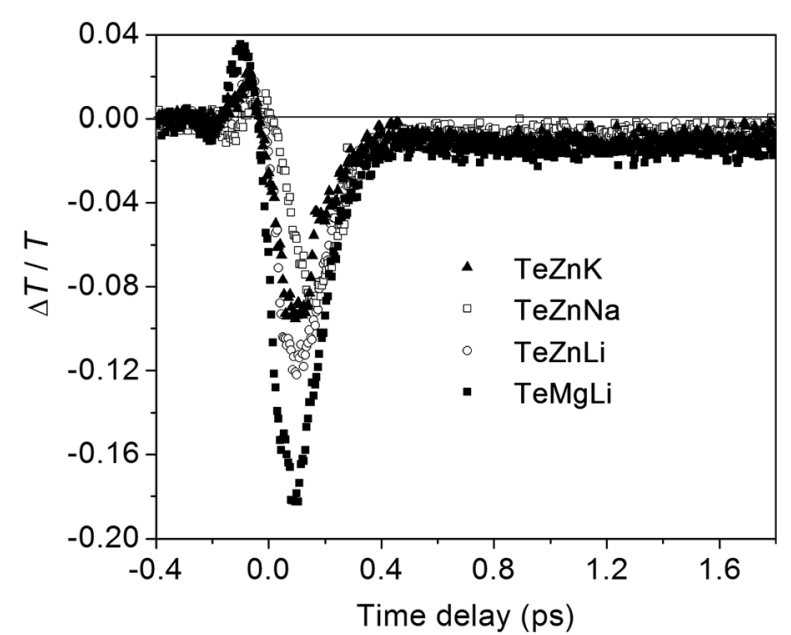

FIG. 7. Transient changes of transmission of samples for pump pulses at $440 \mathrm{~nm}(2.8 \mathrm{eV})$ and probe pulses at $516 \mathrm{~nm}(2.4 \mathrm{eV})$.

might not represent population dynamics of electronic states, but a coherent artifact produced by third-order nonlinear effects, i.e., cross phase modulation effects. In any case, these experiments confirm the existence of localized states and also demonstrate the fast response of the material.

Finally, it is expected that the localized states have a small effect on the nonlinearities of the glasses at nonresonant frequencies, i.e., those optical frequencies at which Zscan experiments were performed. Note that the optical bandgap in glasses plays a role in defining the magnitude of their nonlinearities, for example, it has been observed that nonlinearities increase as the energy gap decreases. ${ }^{25,28}$ Thus, according to this description, the localized states of our tellurite glasses, as well as other disorders in amorphous materials, only produce weak absorption tails in the forbidden energy band, so that they should not modify substantially the nonlinear response. Nevertheless, for optical frequencies in resonance, the localized states can induce enhanced nonlinearities, i.e., multiphoton absorption.

\section{CONCLUSIONS}

The third-order NL optical behavior of tellurite-based glasses with three different alkali metal oxides $R_{2} \mathrm{O}(R=\mathrm{Li}$, $\mathrm{Na}, \mathrm{K}$ ) as network modifiers and $\mathrm{ZnO}$ and $\mathrm{MgO}$ as network intermediates was investigated. It was found that the thirdorder nonlinear optical response at $800 \mathrm{~nm}$ is due to the electronic polarization with negligible thermo-optical contribution. The maximum NL refractive index of $n_{2}=2.81$ $\times 10^{-15} \mathrm{~cm}^{2} / \mathrm{W}$ was obtained for samples with $\mathrm{Li}$ as modifier and $\mathrm{Mg}$ as intermediate. This large $n_{2}$ value is attributed to an increase in hyperpolarizability of samples with $\mathrm{Li}$ and $\mathrm{Mg}$ as a result of their small ionic radii. All glasses exhibit two visible emission bands which can be excited through different excitation wavelengths. Both emission bands originate from optical transitions that include electronic states with smaller energies than the optical bandgap of the tellurite glasses. Those bands are associated to defects produced during the glass fabrication and the presence of modifiers. The presence of such defect states was confirmed by pump-probe experiments. Our experimental results provide new 
information to gain understanding on the nonlinear and luminescent properties of tellurite glasses. It is demonstrated that $\mathrm{TeO}_{2}-\mathrm{MO}-\mathrm{R}_{2} \mathrm{O}$ glasses, whose properties can be optimized by changing the modifiers, are excellent candidates for alloptical switching devices operating in the near infrared.

\section{ACKNOWLEDGMENTS}

This work was partially supported by CONACyT (Ref. J49512-F) and CONCYTEG (Ref. 09-04-K662-072 and 0904-K662-055). R.C.-B., H.D. and S.R-.S. acknowledge CONACYT for Ph.D. scholarships.

${ }^{1}$ R. Rolli, M. Montagna, S. Chaussedent, A. Monteil, V. K. Tikhomirov, and M. Ferrari, Opt. Mater. 21, 743 (2003).

${ }^{2}$ J. Jackson, C. Smith, J. Massera, C. Rivero-Baleine, C. Bungay, L. Petit, and K. Richardson, Opt. Express 17, 9071 (2009).

${ }^{3}$ S. Shen, A. Jha, X. Liu, M. Naftaly, K. Bindra, H. J. Bookey, and A. K. Kar, J. Am. Ceram. Soc. 85, 1391 (2002).

${ }^{4}$ X. Feng, W. H. Loh, J. C. Flanagan, A. Camerlingo, S. Dasgupta, P. Petropoulos, P. Horak, K. E. Frampton, N. M. White, J. H. Price, H. N. Rutt, and D. J. Richardson, Opt. Express 16, 13651 (2008).

${ }^{5}$ P. V. dos Santos, M. V. D. Vermelho, E. A. Gouveia, M. T. de Araújo, F. C. Cassanjes, S. J. L. Ribeiro, and Y. Messaddep, J. Chem. Phys. 116, 6772 (2002).

${ }^{6}$ S. Xu, H. Ma, D. Fang, Z. Zhang, and Z. Jiang, Mater. Lett. 59, 3066 (2005).

${ }^{7}$ M. Dutreilh-Colas, P. Thomas, and J. C. Champarnaud-Mesjard, Phys. Chem. Glasses 44, 349 (2003).

${ }^{8}$ F. Chen, T. Xu, S. Dai, Q. Nie, X. Shen, J. Zhang, and X. Wang, Opt. Mater. 32, 868 (2010).

${ }^{9}$ A. P. Mirgorodsky, M. Soulis, P. Thomas, and T. Merle-Méjean, Phys. Rev. B 73, 134206 (2006).

${ }^{10}$ R. F. Souza, M. A. R. C. Alencar, J. M. Hickmann, R. Kobayashi, and L. R. P. Kassab, Appl. Phys. Lett. 89, 171917 (2006).

${ }^{11}$ F. Eroni. P. dos Santos, F. C. Fávero, A. S. L. Gomes, J. Xing, Q. Chen, M. Fokine, and I. C. S. Carvalho, J. Appl. Phys. 105, 024512 (2009).

${ }^{12}$ J. C. McLaughlin, S. L. Tagg, and J. W. Zwanziger, J. Phys. Chem. B 105, 67 (2001).

${ }^{13}$ J. S. Wang, E. M. Vogel, and E. Snitzer, Opt. Mater. 3, 187 (1994).
${ }^{14}$ H. Lin, S. Jiang, J. Wu, F. Song, N. Peyghambarian, and E. Y. B. Pun, J. Phys. D: Appl. Phys. 36, 812 (2003).

${ }^{15}$ Y. Gao and C. Cramer, Solid State Ionics 176, 2279 (2005).

${ }^{16}$ S. P. Singh, Aman, and A. Tarafder, Bull. Mater. Sci. 27, 281 (2004).

${ }^{17}$ H. Takebe, Y. Nageno, and K. Morinaga, J. Am. Ceram. Soc. 77, 2132 (1994).

${ }^{18}$ H. Desirena, A. Schülzgen, S. Sabet, G. Ramos-Ortiz, E. de la Rosa, and N. Peyghambarian, Opt. Mater. 31, 784 (2009).

${ }^{19}$ M. Sheik-Bahae, A. A. Said, and E. W. Van Stryland, Opt. Lett. 14, 955 (1989).

${ }^{20}$ A. Gnoli, L. Razzari, and M. Righini, Opt. Express 13, 7976 (2005).

${ }^{21}$ F. E. P. dos Santos, C. B. de Araújo, A. S. L. Gomes, K. Fedus, G. Boudebs, D. Manzani, and Y. Messaddeq, J. Appl. Phys. 106, 063507 (2009).

${ }^{22}$ A. S. L. Gomes, E. L. Falcão Filho, and C. B. de Araújo, Opt. Express 15, 1712 (2007).

${ }^{23}$ J. Tauc, R. Grigorovici, and A. Vancu, Phys. Status Solidi 15, 627 (1966).

${ }^{24}$ L. M. Sharaf El-Deen, M. S. Al Salhi, and M. M. Elkholy, J. Alloys Compd. 465, 333 (2008).

${ }^{25}$ S.-H. Kim, T. Yoko, and S. Sakka, J. Am. Ceram. Soc. 76, 2486 (1993).

${ }^{26}$ E. Yousef, M. Hotzel, and C. Rüssel, J. Non-Cryst. Solids 353, 333 (2007).

${ }^{27}$ R. A. Ganeev, A. I. Ryasnyansky, M. Baba, M. Suzuki, N. Ishizawa, M. Turu, S. Sakakibara, and H. Kuroda, Appl. Phys. B 78, 433 (2004).

${ }^{28}$ S.-H. Kim, J. Mater. Res. 14, 1074 (1999).

${ }^{29}$ Q. Liu, C. Gao, H. Zhou, B. Lu, X. He, Q. Shixiong, and X. Zhao, Opt. Mater. 32, 26 (2009).

${ }^{30}$ H. Guo, H. Tao, S. Gu, X. Zheng, Y. Zhai, S. Chu, X. Zhao, S. Wang, and Q. Gong, J. Solid State Chem. 180, 240 (2007).

${ }^{31}$ S. M. Lima, W. F. Falco, E. S. Bannwart, L. H. C. Andrade, R. C. de Oliveira, J. C. S. Moraes, K. Yukimitu, E. B. Araújo, E. A. Falcão, A. Steimacher, N. G. C. Astrath, A. C. Bento, A. N. Medina, and M. L. Baesso, J. Non-Cryst. Solids 352, 3603 (2006).

${ }^{32}$ D. H. Zhang, Z. Y. Xue, and Q. P. Wang, J. Phys. D: Appl. Phys. 35, 2837 (2002).

${ }^{33}$ J. W. P Hsu, D. R. Tallant, R. L. Simpson, N. A. Missert, and R. G. Copeland, Appl. Phys. Lett. 88, 252103 (2006).

${ }^{34}$ S. A. Studenikin, N. Golego, and M. Cocivera, J. Appl. Phys. 84, 2287 (1998).

${ }^{35}$ R. P. Sreekanth Chakradhar, G. Sivaramaiah, J. Lakshmana Rao, and N. O. Gopal, Mod. Phys. Lett. B 19, 643 (2005).

${ }^{36}$ A. Berthereau, Y. Le Luyer, R. Olazcuaga, G. Le Flem, M. Couzi, L. Canioni, P. Segonds, L. Sarger, and A. Ducasse, Mater. Res. Bull. 29, 933 (1994). 